\title{
Análise da cobrança extrajudicial no município de Santa Maria (RS)
}

\section{RESUMO}

Silvia Maria Parmeggiani Gering spgering@hotmail.com

Universidade Federal de Santa Maria. Santa Maria. Rio Grande do Sul. Brasil.

Ricardo da Rosa Nogueira xricardonogueira@gmail.com Universidade Federal de Santa Maria. Santa Maria. Rio Grande do Sul. Brasil.

\section{Greice Eccel Pontelli}

grace pontelli@yahoo.com.br Universidade Federal de Santa Maria. Santa Maria. Rio Grande do Sul. Brasil.

Nelson Guilherme Machado Pinto nelguimachado@hotmail.com

Universidade Federal de Santa Maria.

Santa Maria. Rio Grande do Sul. Brasil.

Fernando do Nascimento Lock fernandolock@hotmail.com

Universidade Federal de Santa Maria Santa Maria. Rio Grande do Sul. Brasil.

\begin{abstract}
A Prefeitura de Santa Maria (RS) buscando aumentar a arrecadação própria implantou, após a vigência da Lei Federal no 12.767/ 2012, a cobrança de débitos através do envio das Certidões de Dívida Ativa para protesto extrajudicial. O objetivo do presente artigo foi analisar o panorama dessa nova modalidade de cobrança segundo a percepção dos agentes da administração tributária municipal, no período de 2014 a 2017. Para tal, foram realizadas 10 entrevistas, que após transcrição foram submetidas a análise de conteúdo para sistematizar os dados. As unidades de análise basearam-se na literatura brasileira e internacional que trata da observância fiscal e seus paradigmas. As análises apontaram que os entrevistados em sua maioria destacaram os aspectos positivos dessa cobrança, a qual consolida-se como uma eficaz ferramenta para o combate à inadimplência perante a Prefeitura. Como limitações evidenciam-se a dificuldade de obtenção de dados segregados de receita, sugerindo-se para futuros estudos a confirmação estatística das informações bem como a análise da percepção sob a ótica dos contribuintes.
\end{abstract}

PALAVRAS-CHAVE: Administração Tributária; Inadimplência; Dívida Ativa; Protesto Extra Judicial; Município. 


\section{INTRODUÇÃO}

Os municípios necessitam de recursos para a realização das múltiplas atividades, bem como para propiciar serviços que proporcionem qualidade de vida aos seus habitantes. Assim, a arrecadação própria está cada vez mais em evidência, seja por questões como a expressiva redução das receitas transferidas pelos governos federal e estadual, as exigências da Lei de Responsabilidade Fiscal, a vinculação das receitas municipais e a necessidade da adoção de princípios de governança; essa conjuntura tem conduzido para que os municípios realizem ações para melhorar a sua administração tributária. Logo, é imperativo que as atividades de arrecadação sejam desenvolvidas de forma a combater a inadimplência, a sonegação e a evasão fiscal.

A melhoria do sistema de cobrança tributária municipal não é algo simples, sendo necessário observar as diversas questões envolvidas. Nessa seara observase que diversos fatores influenciam a decisão do contribuinte sobre o pagamento dos tributos. Assim, verificam-se dois paragdimas concentuais do cumprimento fiscal, sendo o "paradigma do serviço" relacionado à observância voluntária e o "paradigma do crime" à observância forçada. Dependendo do comportamento do contribuinte deverá haver a ação correspondente, salientando-se que para o último deverá haver uma ação mais enérgica por parte do fisco (Silva, 2015).

Contudo, apesar dos esforços efetuados pelas administrações tributárias, verifica-se que os níveis de inadimplência são grandes. Isto foi constatado por Jesus e Rocha (2015) que demonstram que o estoque de dívida ativa representa 35 vezes o valor arrecadado dessa receita, para a maioria dos municípios brasileiros. No município de Santa Maria - RS, objeto do presente artigo, tal situação não é diferente, pois em dezembro de 2016 o valor do estoque da Dívida Ativa correspondia a $48,85 \%$ do valor do orçamento anual, enquanto que a projeção de recebimento dessa receita equivalia, somente a $2,17 \%$ do estoque total da dívida ativa.

Esses expressivos níveis de inadimplência têm sido combatidos pela autoridade tributária municipal, que apesar do alto volume de dívida, tem despontando no cenário nacional com inovações em relação ao processo de cobrança. Nesse ínterim o município vem adotando medidas de informatização de seus cadastros, realização de convênios com outros entes e terceirizando parte da cobrança. Assim, após a publicação da Lei Federal (12.767/2012) o Município, implantou, posteriormente a realização de várias ações, a cobrança das Certidões de Dívida Ativa - CDA via protesto extrajudicial. Essa dinâmica, de acordo com Souza (2015) caracteriza-se por ser um instrumento ágil e eficaz na cobrança de débitos, alternativo à judicialização, sendo seu principal foco a pressão para o pagamento da dívida, em vista de restrições para obtenção de crédito. Além disso, é recomendado com vistas a inibir a inadimplência, e contribuir com a redução do volume de execuções fiscais ajuizadas, resultando na diminuição dos gastos públicos com a cobrança, e ao mesmo tempo, promovendo incremento de receita (Elch, Pimentel, Moura \& Casanova Neto, 2014; TCE, 2014).

Dada essa contextualização, essa pesquisa objetiva estudar o panorama da cobrança extrajudicial após a Lei Federal (12.767/2012) segundo a percepção dos agentes da administração tributária municipal, sendo analisado o processo realizado no período de 2014 a 2017. Entende-se que para resolver os problemas da inadimplência, é fundamental que a arrecadação municipal dos tributos seja 
realizada em sua plenitude, atingindo os níveis totais legalmente estabelecidos, de acordo com a Lei de Responsabilidade Fiscal. Assim, buscam-se alternativas para contribuir com o acréscimo da receita própria, tão necessário nos municípios em vista do período em que se vive. Por outro lado, a melhoria dos serviços públicos e a adequada comunicação entre o fisco e os cidadãos se mostram como consistente mecanismo de favorecimento a observância tributária.

As justificativas deste artigo enquadram-se no cenário brasileiro, no qual ocorrem duras críticas à alta carga tributária imposta às empresas e as pessoas físicas. Além disso, a inadimplência atua desfavoravelmente no equilíbrio financeiro. Em vista disso, as administrações municipais devem trabalhar em prol do aumento da eficiência de seus processos de arrecadação na aplicação da receita própria, sem instituir aumento da carga tributária. Portanto, a relevância do estudo em termos práticos é proporcionar aos demais municípios brasileiros o entendimento do panorama de implantação de melhoria da administração tributária segundo a percepção de seus agentes, de modo a contribuir para a elaboração de estratégias e planos de cobrança, baseadas numa experiência real. Do mesmo modo, a relevância teórica deste trabalho está em aprofundar os estudos da gestão pública, especificadamente na área da tributação municipal, ainda escassos dentro da literatura brasileira. Além dessa introdução, o artigo está estrutura nos seguintes capítulos: referencial teórico, método, análise dos resultados, considerações finais e as referências.

\section{REFERENCIAL TEÓRICO}

\subsection{Inadimplência Fiscal}

Quando os tributos não são recolhidos pelos contribuintes ou arrecadados pelo órgão público, configura-se a inadimplência. Assim, essa pode ser caracterizada como a falta de pagamento ou o não-cumprimento de um contrato ou cláusula, ou seja, a não-satisfação da obrigação no prazo determinado. Nesse sentido o inadimplemento se refere ao fato de o devedor descumprir ao que se obrigou, seja voluntariamente ou involuntariamente (Rizzardo, 2015). Salienta-se que na esfera pública o inadimplemento tem como particularidade ser oriundo da sujeição passiva do contribuinte em relação a obrigação tributária (Amaro, 2016). Isso decorre do §1을. 113 do CTN (Brasil, 1966) que estabelece que "a obrigação principal surge com a ocorrência do fato gerador, e tem por objeto o pagamento de tributo". Logo, contribuinte inadimplente é aquele que não quita os tributos na data do vencimento, ou não presta as informações solicitadas com vistas a reduzir o quantum a pagar.

Em relação ao perfil do contribuinte inadimplente salienta-se que existem vários grupos com distintos comportamentos, abrangendo desde aquele fiel cumpridor de suas obrigações até aquele que comete fraudes e crimes fiscais complexos. Destacando-se que o contribuinte, normalmente paga impostos baseado na avaliação do risco de ser surpreendido e de acordo com o valor das penalidades (Viol, 2015). O entendimento tradicional do comportamento de conformidade fiscal depende em grande parte da coerção, supondo que se os cidadãos não sejam obrigados a declarar e pagar impostos, não o farão. Essa premissa, indica que as autoridades tributárias devem focar na diminuição da 
evasão através de auditorias e penalidades pelo descumprimento fiscal. Contudo, apesar da importância dessa austeridade tributária, não existem comprovações estatísticas significativas em relação ao comportamento do contribuinte e a ameaça de punição (Kirchler, Hoelzl, \& Wahl, 2008).

Dessa forma, os níveis de conformidade fiscal estão relacionados aos conjuntos de medidas arrecadatórias, como ainda pelas atitudes dos contribuintes em relação à tributação e ao governo em geral. Sendo que o comportamento do contribuinte é formado por fatores como: percepção da evasão, justiça tributária, complexidade fiscal, estabilidade, forma de administração, valor atribuído às atividades governamentais e legitimidade do governo (Bird, 2014).

Nesse contexto, a observância tributária pode ser alicerçada em dois eixos conceituais: o "paradigma do crime" e o "paradigma do serviço". Salienta-se que o "paradigma do crime" tem como consequência que o contribuinte no momento de decidir pelo cumprimento de suas obrigações fiscais, verifica os riscos e benefícios, pressupondo sua racionalidade. Assim, quando os riscos aumentam, o contribuinte tenderá a pagar integralmente seus tributos. Logo, a observância fiscal, pode ser encorajada através de fiscalizações ou punições, sendo a cooperação relegada a segundo plano. O contrário ocorre no "paradigma do serviço", onde a observância é decorrente de ato voluntário do contribuinte. Nesta existe a interação respeitosa entre os contribuintes e o fisco, fortalecida pela confiança nas autoridades, as quais privilegiam a cooperação. Assim, as autoridades tributárias podem se pautar por ambos os paradigmas para a formulação de suas políticas e processos, além disso, as ações visando a observância voluntária podem ser complementares as realizadas tendo o viés da observância forçada (Silva, 2015).

Diante desse contexto, o contribuinte ao deixar de recolher o imposto é penalizado individualmente e conjuntamente com toda a população, pois a cidade deixa de receber investimentos em obras e serviços de interesse social. Logo, Freire e Freire (2014:1) são enfáticos ao declarar que "identificada a existência da inadimplência, passa a ser necessário detectar suas causas e, a partir disso, trabalhar para evitá-la e diminuir suas consequências". Desse modo é necessária a atuação das administrações tributárias perante a dívida ativa.

\subsection{Dívida Ativa}

A Dívida Ativa compõe a Administração Tributária, e representa todos os valores que a Fazenda Pública tem para receber de terceiros que não foram pagos dentro do prazo legal estabelecido pela legislação (Amaro, 2016). Os art. 201 até art. 204 do CTN (Brasil, 1966) estabelecem que Dívida Ativa regularmente inscrita tem o efeito de prova pré-constituída, e goza da presunção de certeza e liquidez. A Lei Federal no 6.830, de 22 de setembro de 1980 (Brasil, 1980), dispõe sobre a cobrança judicial de Dívida Ativa da Fazenda Pública, no âmbito da União, Estados e Municípios. A partir da inscrição em Dívida Ativa, procedimento que será feito pelo órgão competente para apurar a liquidez e certeza do crédito, ocorre a emissão da Certidão de Dívida Ativa - CDA. De acordo com o Inciso IX do art. 784, da Lei Federal 13.105, de 16 de março de 2015, que estabelece o Código de Processo Civil - CPC (Brasil, 2015), a CDA enquadra-se como um título executivo extrajudicial. 
Os números das inobservâncias tributárias são alarmantes, sendo que a Dívida Ativa Tributária da União, segundo o balanço geral da união do segundo trimestre de 2017 (Brasil, 2017) representa R\$ 1,935 trilhões, sendo que o Ministério da Fazenda responde por 99,99\% da Dívida Ativa Tributária bruta. A dívida não tributária da União totaliza $\mathrm{R} \$ 65$ trilhões, estando distribuída em vários órgãos. No caso dos municípios, os índices também são elevados, de acordo com Jesus e Rocha (2015), o valor do estoque de dívida ativa pode ter atingido em 2014 $\mathrm{R} \$ 241,52$ bilhões, ao mesmo tempo que a receita dos créditos tributários e não tributários, no mesmo período, pode ter alcançado, apenas, o valor de $\mathrm{R} \$ 6,97$ bilhões. Assim, de acordo com Jesus e Rocha (2015:37) "para a maioria dos Municípios, o estoque de dívida ativa representa 35 vezes o valor arrecadado dessa receita".

Destaca-se conforme Jesus e Rocha (2015) que os principais motivos para os municípios não efetuarem a cobrança da dívida ativa são: problemas de estrutura física e falta de recursos humanos capacitados com conhecimento prático e teórico; falta de recursos tecnológicos e inconfiabilidade dos dados; falhas na emissão da CDA; falhas na fiscalização executada pelas administrações; desgaste político; dificuldades na localização de contribuinte devedor; dificuldade em localizar bens que satisfaçam o crédito público, e ainda, o aspecto econômico da sociedade local. Nesse sentido, é unânime que os municípios devem buscar realizar a cobrança desses recursos que são líquidos e certos. Para tanto, segundo orienta a Cartilha de Racionalização do Tribunal de Contas do Estado do Rio Grande do Sul (TCE, 2014), na fase que precede a emissão da CDA, é importante o controle da legalidade. Logo, são imprescindíveis as verificações do nome do devedor, do CPF ou CNPJ, da atualização do endereço, da exatidão do valor devido, da correção quanto à fundamentação legal; objetivando as correções necessárias para a eficácia das execuções judiciais.

Em relação às formas de recuperação dos valores inscritos em Dívida Ativa têm-se a cobrança amigável e judicial. A conciliação amigável é um meio rápido de alavancar a arrecadação, contudo, o que as evidências empíricas demonstram é que fatores diretamente relacionados a ausência de estrutura física, material, humana, e vontade política, tem frustrado essa oportunidade. Da mesma forma, a ação judicial, também enfrenta problemas, pois, dos processos que passam a etapa da citação, poucos vão para penhora de bens, leilão, arrematação ou adjudicação. Portanto, deve-se pensar a qualidade do crédito e reavaliar o processo como um todo para obtenção de êxito (Elch, et al., 2014; TCE, 2014).

O Protesto Extrajudicial da CDA foi instituído pela Lei no 12.767, de 27 de dezembro de 2012 (Brasil, 2012), que inseriu o Parágrafo único no art. 1ㅇ da Lei no 9.492, de 10 de setembro de 1997 (Brasil, 1997), que diz que "incluem-se entre os títulos sujeitos a protesto as certidões de dívida ativa [...]". Tal procedimento é recomendado com vistas a agilizar o pagamento, inibir a inadimplência, e contribuir com a redução do volume de execuções fiscais ajuizadas, resultando na diminuição dos gastos públicos com a cobrança, e ao mesmo tempo, promovendo incremento de receita (Elch et al., 2014; TCE, 2014). Destaca-se que o protesto extrajudicial é um instrumento moderno, ágil e eficaz na cobrança de débitos, alternativo à judicialização, sendo seu principal foco a pressão para o pagamento da dívida, em vista de restrições para obtenção de crédito. Tal instrumento, não é privilégio dos órgãos públicos, pois o devedor também é alcançado por este, quando o credor é de órgão privado. Assim, seu alto grau de eficiência na 
recuperação do crédito, sem intervir diretamente no patrimônio do devedor, atende não apenas a importância arrecadatória, mas também ao interesse público da coletividade, devendo ser estimulado (Souza, 2015).

\section{MÉTODO}

O processo metodológico do presente artigo foi realizado em cinco etapas sequenciais: revisão teórica, aplicação de entrevistas, transcrição/organização/categorização das respostas, levantamento documental e análise de dados. Para atender aos objetivos do estudo optou-se pela realização de um estudo de caso, de forma descritiva, com abordagem qualitativa.

Com base no levantamento da teoria, foi desenvolvido um instrumento para a aplicação das entrevistas semi-estruturadas, sendo as questões ancoradas na literatura acadêmica previamente pesquisada. Assim, o inquérito inicial contou com 23 perguntas, que após pré-teste através de entrevista piloto, resultou em um instrumento final com 22 questões. Foram realizadas 10 entrevistas, no período de 05/09/2017 à 22/09/2017, com os agentes da administração tributária da entidade analisada. Observa-se também que todos os entrevistados concordaram em participar da pesquisa, sendo que as orientações, esclarecimento de dúvidas e responsabilidades dos envolvidos constam em um Termo de Consentimento Livre e Esclarecido. Dessa forma, para proteger a identidade dos entrevistados, seus nomes foram substituídos pelos códigos R1, R2, R3, R4, R5, R6, R7, R8, R9 e R10, conforme Tabela 1.

Tabela 1 - Síntese dos entrevistados

\begin{tabular}{|c|l|c|c|c|}
\hline Entrevista & $\begin{array}{c}\text { Área de } \\
\text { Formação }\end{array}$ & $\begin{array}{c}\text { Especialização na } \\
\text { área pública }\end{array}$ & $\begin{array}{c}\text { Tempo de serviço na } \\
\text { organização (em } \\
\text { anos) }\end{array}$ & $\begin{array}{c}\text { Duração da } \\
\text { entrevista (em } \\
\text { minutos) }\end{array}$ \\
\hline Piloto & Econômica & Sim & 19 & 29 \\
\hline R1 & Engenharia & Sim & 12 & 40 \\
\hline R2 & Administrativa & Sim & 0,75 & 31 \\
\hline R3 & Administrativa & Sim & 36 & 80 \\
\hline R4 & Educacional & Sim & 15 & 20 \\
\hline R5 & Contabilidade & Não & 2 & 16 \\
\hline R6 & Sociais & Não & 7 & 26 \\
\hline R7 & Contabilidade & Sim & 17 & 19 \\
\hline R8 & Outras & Não & 33 & 32 \\
\hline R9 & Direito & Sim & 6 & 57 \\
\hline R10 & Direito & Sim & 6 & 47 \\
\hline
\end{tabular}

Fonte: Elaborado pelos autores.

Após a realização das entrevistas, as mesmas foram transcritas na sua literalidade, o que permitiu aos pesquisadores categorizar as respostas utilizando método da análise de conteúdo (Bardin, 2011). Dessa análise surgiram as classificações descritas na Tabela 2, que evidencia a categorização das entrevistas. 
Tabela 2 - Categorização das entrevistas

\begin{tabular}{|c|c|}
\hline Categoria & Subcategorias \\
\hline \multirow{2}{*}{ Inadimplência } & Causas \\
\hline & Como afeta o município \\
\hline \multirow{2}{*}{ Cobrança } & Estrutura \\
\hline & Ações administrativas \\
\hline \multirow{5}{*}{ Protesto extrajudicial de Dívida Ativa } & Implantação \\
\hline & Soluções decorrentes \\
\hline & Consequências para o município \\
\hline & Vantagens \\
\hline & Limitações \\
\hline \multirow{3}{*}{ Contribuinte } & Perfil \\
\hline & Comportamento \\
\hline & Consequências para o contribuinte \\
\hline \multirow{3}{*}{ Temas emergentes } & Boas práticas \\
\hline & Alteração Lei Orgânica \\
\hline & Bônus adimplência \\
\hline
\end{tabular}

Fonte: Elaborado pelos autores.

O levantamento documental foi realizado com base nas publicações oficiais disponíveis na internet, sendo complementada com informações buscadas diretamente junto à Prefeitura Municipal. Essa etapa da pesquisa objetivou coletar documentos (leis, decretos, regulamentos, organogramas, instruções normativas, portarias, contratos) e dados quantitativos (composição da receita municipal, estoque da dívida ativa, quantidade lançamentos efetuados no SCPC e valores recuperados). A Figura 1 sintetiza os procedimentos metodológicos do presente estudo.

Figura 1 - Síntese dos procedimentos metodológicos

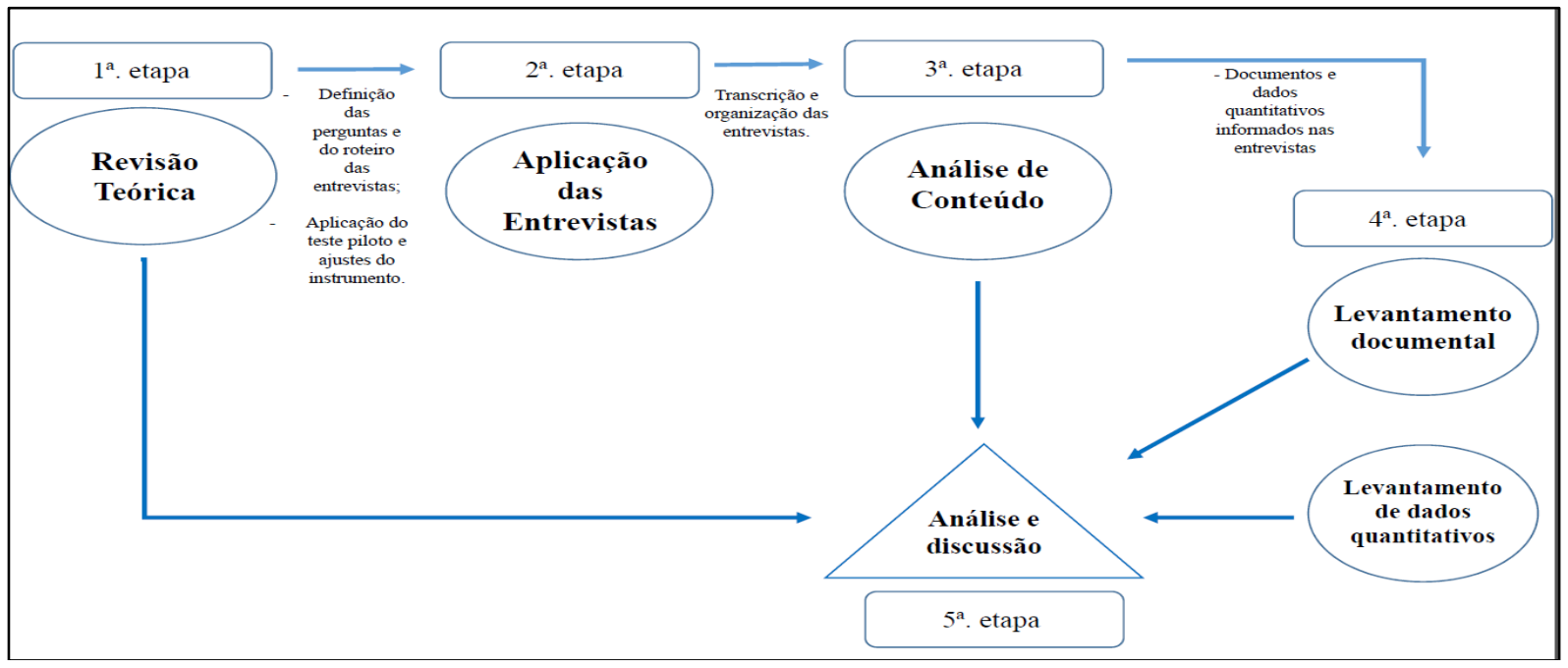

Fonte: Elaborado pelos autores.

Com a posse dos dados documentais, foi possível aplicar a triangulação entre as entrevistas, os dados documentais e resultados quantitativos da Prefeitura, buscando dessa forma aumentar a validade da pesquisa. 


\section{APRESENTAÇÃO DOS RESULTADOS}

Na Prefeitura Municipal de Santa Maria - PMSM verifica-se que são altos os índices de inadimplência referente aos débitos, pois esses valores ocasionam acréscimos do estoque de Dívida Ativa. O Figura 2 demonstra o estoque de dívida ativa tributária e não tributária, do período de 2010 até 2016, apresentando o saldo a receber, no último dia do ano, a curto e a longo prazo.

Figura 2 - Estoque de Dívida Ativa PMSM - em UFM¹ - Período de 2010 até 2016

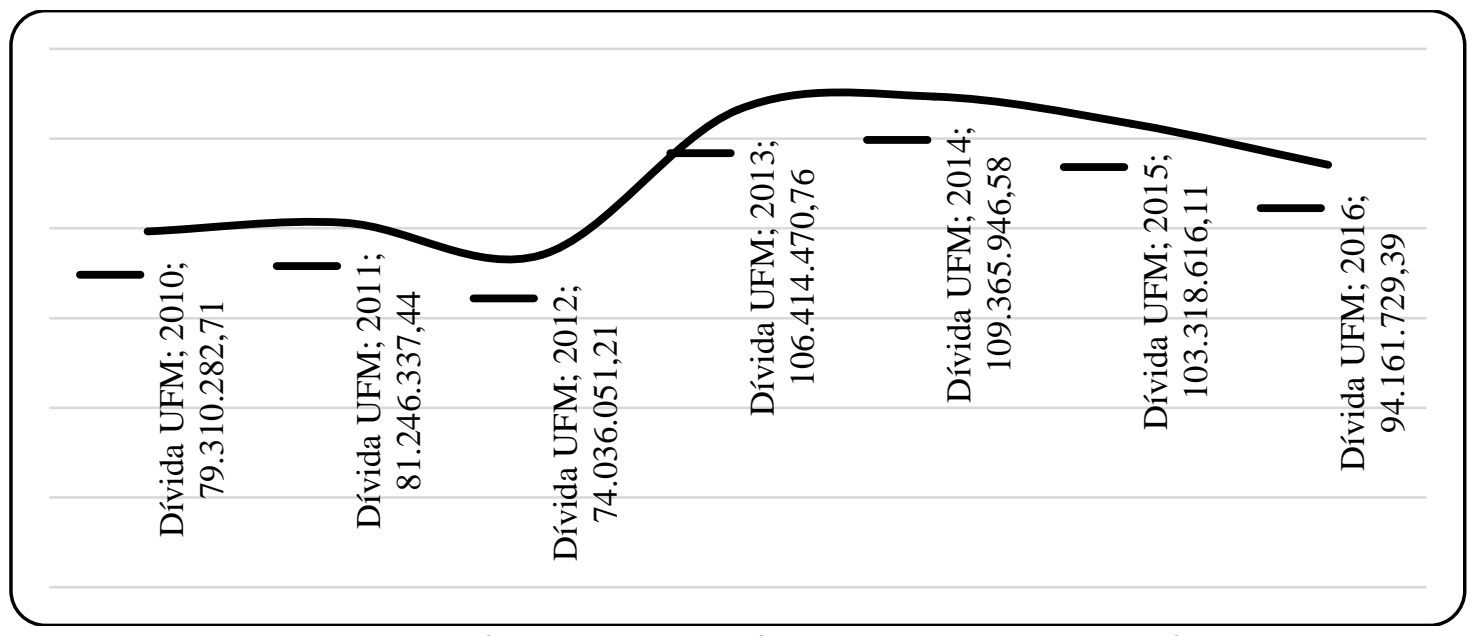

Fonte: Relatórios Superintendência de Gestão Orçamentária e Financeira Secretária de Município das Finanças.

O entrevistado R1 declara que muitas foram as alternativas buscadas para trabalhar em prol do recebimento destes recursos com maior eficiência. Apesar disso, o entrevistado R2 manifesta sua preocupação quanto a possibilidade de recuperação desses valores.

Olha, nós temos um estoque de dívida que equivale a aproximadamente a metade do orçamento anual, eu não acredito assim que todo esse crédito, todo esse volume nós tenhamos na dívida, que seja ele uma dívida que seja efetivamente recuperável. [R2]

Além disso, para demonstrar o volume do estoque de Dívida Ativa no Município efetua-se a comparação deste, referente ao ano de 2016, com o valor da receita prevista no orçamento. Verifica-se que o orçamento anual do ano de 2016 da PMSM correspondeu ao valor de $\mathrm{R} \$ 648,200$ milhões, sendo que a receita de Dívida Ativa prevista neste ano totalizou o valor $\mathrm{R} \$$ 6,870 milhões, enquanto que o estoque de débitos em janeiro desse ano totalizava $\mathrm{R} \$ 316,677$ milhões. Dessa forma, constata-se que o valor do estoque da Dívida Ativa corresponde a $48,85 \%$ do valor do orçamento anual, enquanto que a projeção de recebimento equivale somente a $2,17 \%$ do estoque do ano. Salienta-se que em $31 / 10 / 2017$, o estoque de valores a receber atinge $\mathrm{R} \$ 351,148$ milhões, dos quais $90,47 \%$ correspondem a dívida ativa e 9,53\% a débitos correntes.

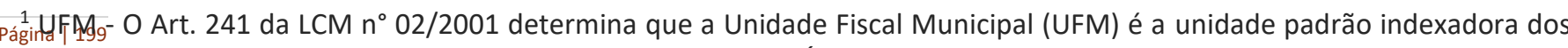
tributos municipais, a qual é reajustada anualmente pelo IPCA (Índice Nacional de Preços ao Consumidor Amplo), e declarada anualmente por Decreto Executivo Municipal. 
No município estudado as causas da inadimplência fiscal podem estar ligadas a diversos fatores com destaque aos socioeconômicos, a percepção do contribuinte em relação à gestão pública, ao volume da carga tributária, a inércia da cobrança administrativa, bem como a demora nos processos judiciais. Os entrevistados R5 caracteriza de diferentes formas os motivos da inadimplência fiscal dos contribuintes da Prefeitura de Santa Maria:

Eles não tinham interesse de pagamento, porque eles sabiam que não existia nenhuma sanção futura sobre isso. [R5]

Apesar de as respostas serem heterogêneas, observa-se que muitos entrevistados consideram como as principais causas da inadimplência as falhas no processo de cobrança e a crise do país, inclusive o desemprego. Nessa linha depara-se com que a inadimplência perante o fisco municipal é oriunda de causas endógenas e exógenas. Assim, quando as causas da ineficiência da administração tributária são provocadas por motivos internos a crise brasileira, os responsáveis pelo fisco da unidade de análise podem adotar medidas para melhoria dos processos de cobrança, bem como o entendimento do comportamento do contribuinte.

Sob a perspectiva teórica a inadimplência fiscal junto à PMSM vai ao encontro de ambos paradigmas de observância fiscal: o clássico paradigma do crime - PC e o contemporâneo paradigma do serviço - PS. Dessa forma as causas relacionadas aos procedimentos de cobrança, as ações de fiscalização e aplicação de penalidades atendem aos pressupostos do PC enquanto que as questões voltadas a educação fiscal, cultura tributária e a prestação de serviços públicos atendem ao PS. O Tabela 3 sintetiza a percepção dos entrevistados quanto as causas da inadimplência junto à PMSM.

Tabela 3 - Causas da inadimplência junto à Prefeitura de Santa Maria - RS

\begin{tabular}{|c|c|c|c|c|c|c|c|c|c|c|}
\hline Causa & R1 & $\mathbf{R 2}$ & R3 & R4 & R5 & R6 & R7 & R8 & R9 & R10 \\
\hline Falhas no processo de cobrança. & & $\mathrm{x}$ & $\mathrm{x}$ & $x$ & $\mathrm{x}$ & & $\mathrm{x}$ & $x$ & & \\
\hline Crise do país/desemprego. & & & $x$ & $\mathrm{X}$ & & $\mathrm{X}$ & $\mathrm{X}$ & & & \\
\hline Cultura/Educação Fiscal. & & & $x$ & $x$ & $x$ & & & & & \\
\hline $\begin{array}{l}\text { Impossibilidade da dívida ser cobrada } \\
\text { judicialmente. }\end{array}$ & & & & & $\mathrm{X}$ & & & & & \\
\hline $\begin{array}{l}\text { Fragilidade no mecanismo de } \\
\text { sanções/penalidades. }\end{array}$ & & & & & $\mathrm{x}$ & & & & & \\
\hline $\begin{array}{l}\text { Questões relacionadas ao parcelamento } \\
\text { tributário. }\end{array}$ & & & & & & $\mathrm{X}$ & & & & \\
\hline $\begin{array}{l}\text { Ausência de contrapartida em serviços } \\
\text { públicos. }\end{array}$ & & & & & & & & $\mathrm{X}$ & & \\
\hline
\end{tabular}

Fonte: Elaborado pelos autores.

$\mathrm{Na}$ área pública, quando os percentuais de inadimplência são elevados, temse como consequência o aumento na carga tributária ou a redução dos bens e serviços públicos, pois o não pagamento por parte de alguns contribuintes será suportado pelos demais. Além desses efeitos, ocasiona descompasso nas ações dos governantes, precarização nas funções alocativas, distributivas e estabilizadoras do Estado, injustiça social e prejuízo aos menos favorecidos. tornando o município mais dependente de outros entes da federação. Dessa 
forma, na composição da receita municipal da PMSM no exercício de 2016, é constante o grau de dependência de recursos externos, pois a receita própria totalizou $32 \%$, enquanto que as receitas transferidas totalizaram $68 \%$.

As entrevistas demonstraram diversas inquietações dos agentes da administração tributária em relação aos efeitos da inadimplência municipal. Uma delas é a dependência das receitas transferidas, bem como a sua redução, pois os governos federal e estadual têm diminuído os valores dos repasses aos municípios, os quais derivam-se de políticas de renúncia fiscal sobre os impostos compartilhados, ou pela criação de tributos na forma de contribuições que não são compartilhadas.

Em contraponto à redução das receitas transferidas e repasses, tem-se a crescente demanda por serviços públicos. Dessa forma, é imperativo que a administração municipal fortaleça a arrecadação própria com ações de combate a inadimplência, a sonegação fiscal como demonstrado na afirmação da entrevista R3:

Os municípios a tendência é, que hoje, o município tem que se aperfeiçoar cada vez mais na cobrança. Por quê? Porque tu não tens mais dinheiro do Governo Federal, o valor é baixo, do Governo do Estado também não vem mais dinheiro, então o município vai ter que se virar com a receita própria, achar dispositivos dentro do município para fazer. [R3]

A busca pelo aumento do percentual de receitas próprias fica evidenciada na resposta do entrevistado $\mathrm{R} 2$, o qual entende que apesar das ações desenvolvidas, o percentual é considerado relativamente baixo se comparado a outras cidades do mesmo porte. Observa-se que os fatores da inadimplência no município estudado possuem algumas causas descritas por Afonso, Araújo e Nóbrega (2013) e Viol (2015). Destaca-se a não efetividade das punições; a negligência e a passividade da cobrança fiscal devido à existência de cadastros desatualizados, a deficiência nos sistemas informatizados, estrutura tributária e processos inadequados; falta de fiscalização e a carência na área de pessoal.

Destarte, como lecionado por Freire e Freire (2014), é necessário que após a identificação da inadimplência sejam detectadas as suas causas, trabalhando para evitá-la e mitigar suas consequências. Assim, serão discutidas nos próximos tópicos as questões relacionadas à administração tributária municipal e as ações para o enfrentamento da inadimplência.

Referente ao processo de cobrança, a análise das entrevistas apontou para um fluxo de cobrança realizado pela PMSM de forma empírica, não havendo o estabelecimento oficial de fluxogramas ou normativa que discipline todo o processo. Essa informação é evidenciada na entrevista R3 "Assim, o que acontece, nós temos um organograma nosso", quanto a rotinas de cobrança de tributos "todo início de ano é feito o que a gente chama de 'Decretão', aí o Decreto ele te diz, o valor que é a UFM no ano, e todas as datas que é vencimento dos tributos". 
Figura 3 - Fluxograma da Cobrança

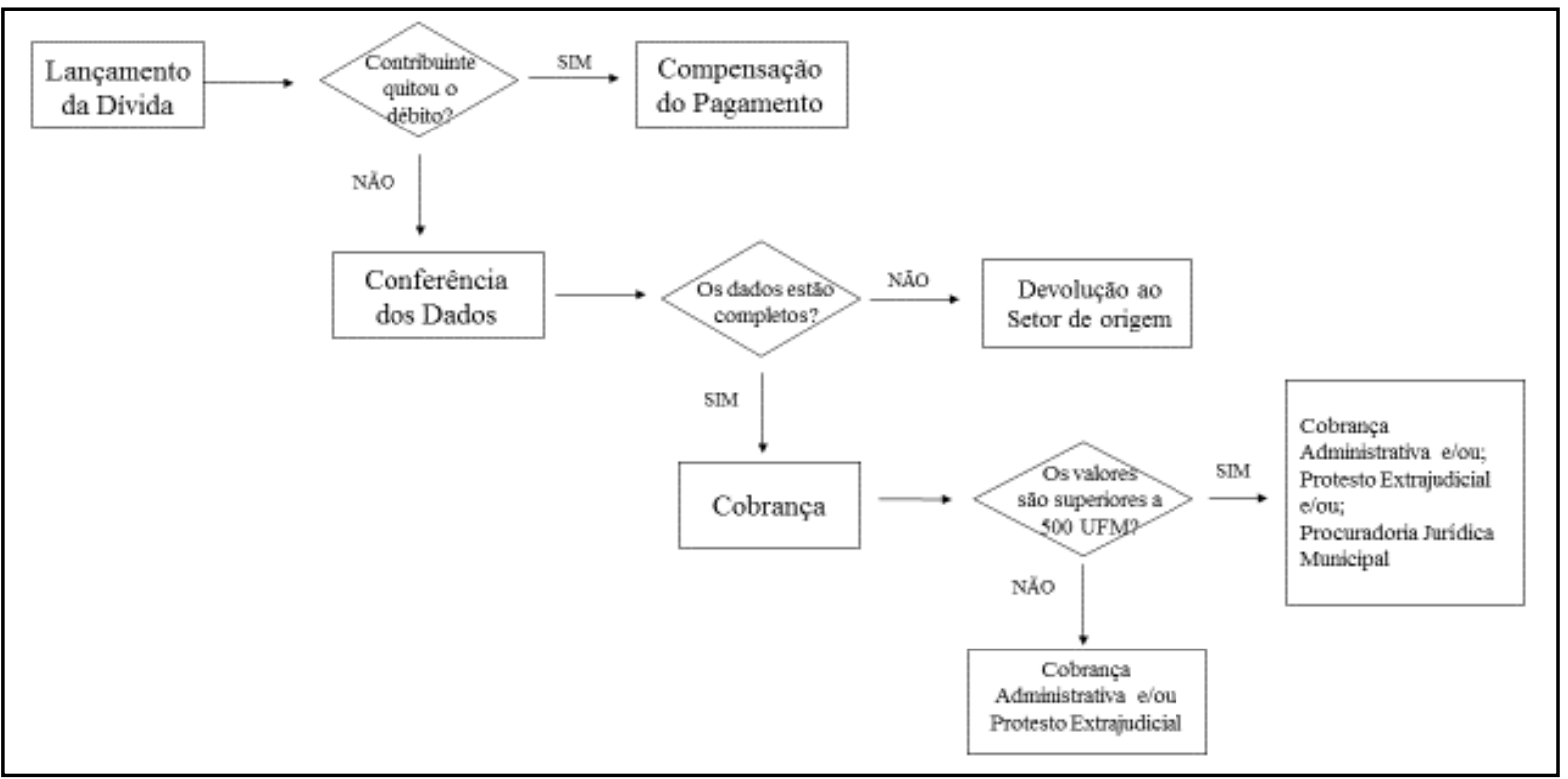

Fonte: Superintendência de Receita - Secretaria de Município das Finanças.

Dessa forma, a estrutura de cobrança no Município de Santa Maria é sintetizada na Figura 3, que demonstra o fluxograma da cobrança.

\section{DISCUSSÃO DOS RESULTADOS}

Várias são as necessidades apontadas pelos respondentes para que a cobrança no município possua maior efetividade. A necessidade informatização, a melhoria nos processos internos, a atualização nos dados cadastrais e a falta de pessoal foram as mais citadas. No Tabela 4 apresenta-se a percepção dos entrevistados em relação a estrutura de cobrança.

Tabela 4 - Percepção da Estrutura da Administração Tributária da PMSM - RS.

\begin{tabular}{|l|c|c|c|c|c|c|c|c|c|c|}
\hline Estrutura de Cobrança. & R1 & R2 & R3 & R4 & R5 & R6 & R7 & R8 & R9 & R10 \\
\hline Falta de confiabilidade nos dados. & X & & X & & & & & & & \\
\hline Necessidade de informatização. & X & X & X & & & & X & & & X \\
\hline Necessidade de melhorias nos processos internos. & & X & & & & & X & X & X & \\
\hline Otimização da estrutura existente. & & $\mathrm{X}$ & & & & & & & & $\mathrm{X}$ \\
\hline Necessidade de regras de compliance. & & $\mathrm{X}$ & & & & & & & & \\
\hline Necessidade de melhoria cadastral. & & $\mathrm{X}$ & $\mathrm{X}$ & & $\mathrm{X}$ & $\mathrm{X}$ & & & & \\
\hline Falta de pessoal. & & & $\mathrm{X}$ & $\mathrm{X}$ & & & $\mathrm{X}$ & & & \\
\hline Necessidade de melhoria na legislação. & & & & & & & & & & \\
\hline $\begin{array}{l}\text { Impossibilidade de ajuizar dívidas menores que } \\
\text { 500 UFM. }\end{array}$ & & & $\mathrm{X}$ & & & & & & & \\
\hline Falta de convênio com outros órgãos. & & & & & $\mathrm{X}$ & & & & \\
\hline Formas de comunicação e meios de pagamentos. & & & & & & & & $\mathrm{X}$ & & \\
\hline
\end{tabular}

Fonte: Elaborado pelos autores. auxílio das administrações tributárias é algo recorrente na literatura conforme 
demonstrado Bird (2014). O entrevistado R8 aponta para a necessidade de melhoria dos canais de comunicação e atendimento ao contribuinte, tornando independente o mesmo na realização de consulta de situação financeira, emissão de guias, parcelamentos e outros serviços. Com esse tipo de serviço disponível para a população, os servidores, após a automatização de processos poderiam ser utilizados para análises de pontos críticos como enfocado pela entrevistado R2.

O trabalho de modernização auxilia na conformidade fiscal, isso é confirmado por Bird (2014). O autor é enfático ao evidenciar que somente uma boa infraestrutura administrativa poderá propiciar a efetividade da atuação do poder tributante, auxiliada por moderna tecnologia da informação, para com isso ter cadastros e processos efetivos para a cobrança. Dessa forma, a percepção do entrevistado R8 é da inadequação da estrutura arrecadatória municipal, bem como, a urgência de soluções.

Outro fator primordial para a efetividade da cobrança é a atualização cadastral, ou seja, o cadastro do contribuinte tem que estar completo, sendo relatado nas entrevistas que tais fatores afetam a eficiência da cobrança. Salientase que as conferências dos dados são executadas somente para as inscrições de dívida ativa relativas às notificações de lançamento de impostos, notificações de auto de infração, e processos administrativos de devolução de valores. Para os demais tributos, o lançamento em dívida ativa é em lote e não existem filtros no sistema, o que pode ser confirmado pelo respondente R8. Tal fato denota uma falha no processo, pois a legislação tributária prevê a certeza e liquidez da Certidão de Dívida Ativa.

Conforme apurado na pesquisa, o município adota as cobranças administrativa e judicial para recuperar os valores inscritos em Dívida Ativa. A conciliação administrativa, conforme relato dos entrevistados é um meio rápido de alavancar a arrecadação, contudo, as evidências demonstram que fatores diretamente relacionados à ausência de estrutura física, material, humana, e vontade política, estão dificultando os resultados desse tipo de cobrança. Por outro lado, o processo de cobrança judicial, também enfrenta dificuldades, principalmente quando não há acordo, em virtude de poucos processos terminarem com o sucesso na penhora dos bens. Apesar dos problemas, a entrevista R9 revela o bom nível de cobrança judicial "hoje nós estamos muito padronizados, em condutas e procedimentos, chega um processo, primeiro tal coisa, segundo tal coisa, existe uma ordem e uma lógica padrão".

Outro modo de cobrança da Dívida Ativa que esteve em pauta foi a terceirização da cobrança, a qual foi permitida pela Resolução n. 33, de 13/06/2006, do Senado Federal, a qual previa a possibilidade de ceder a dívida ativa às instituições financeiras, através de lei específica. Nesse caso, o banco faria a cobrança por endosso/mandato, com a antecipação da receita pelo seu valor de face. Essa resolução não passou despercebida pelo município, que declarou que esse tipo de cobrança esbarra no interesse das instituições bancárias em realizar esses procedimentos para a Prefeitura. A entrevista R3 revela sua percepção quanto ao assunto: coisa que vai dar resultado, por exemplo tu vai vender a tua Dívida Ativa, por exemplo tem várias empresas, várias assessorias que dizem que é para o município vender a sua Dívida Ativa, mas se tu vais chegar no banco e propor para vender, o banco não vai 
querer, porque o banco não vai querer ficar com esse valor que não vai ter como cobrar, porque se o município já tentou, Cartório, SCPC, como é que o banco vai conseguir? [R3]

Apesar das demonstrações da ineficiência na estrutura o município mantevese atuante em relação a cobrança dos débitos. Assim, com a publicação da Lei Federal no 12.767, de 27 de dezembro de 2012 (Brasil, 2012), foi vislumbrada a possibilidade de melhoria no processo de cobrança administrativa dos débitos municipais, haja vista que a nova legislação permitiu o protesto extrajudicial da certidão de dívida ativa - CDA.

O processo de implantação da cobrança dos débitos municipais através do protesto extrajudicial da certidão de dívida ativa - CDA, segundo o entrevistado R1, ocorreu na PMSM de forma gradativa e em alguns momentos não intencional, conforme declara: "Então, foi com essa finalidade o início da legislação do CADIM, depois ela evoluiu, porque a lei nos permitiu, mas não foi a ideia inicial". Segundo o relato, a Prefeitura inicialmente procurava sistematizar os seus cadastros e controles de cobrança, para isso criou o Cadastro de Informações Municipais CADIM. Essa sistematização era necessária em virtude dos grandes volumes de créditos devidos ao município conforme relato do entrevistado R1.

A Figura 4 remonta a sequência dos fatos mais importantes para esse novo procedimento da Administração Tributária.

Figura 4 - Linha do tempo da implantação do processo de cobrança via extrajudicial da CDA.

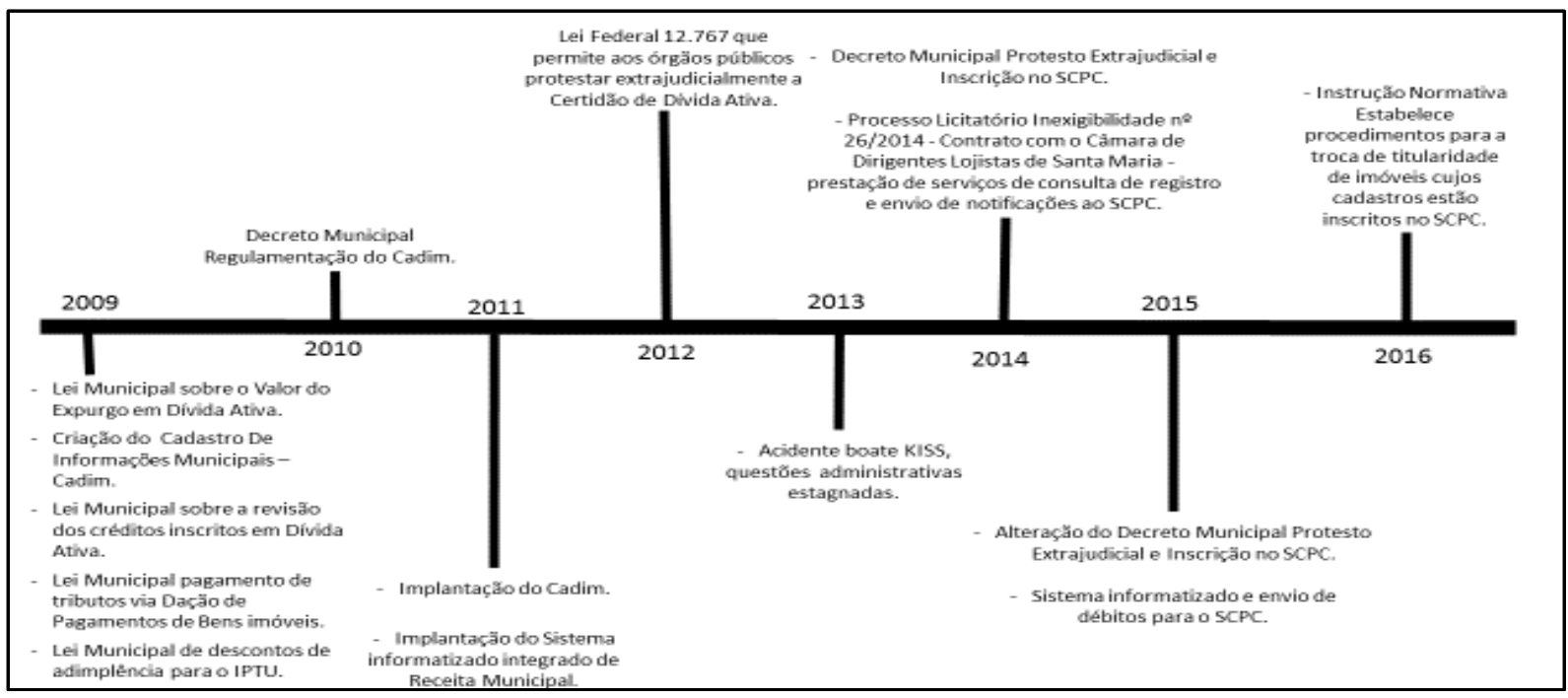

Fonte: Entrevistas realizadas e site da PMSM.

O entrevistado R1 relata que em 2009 começou a ser produzido no município um conjunto de legislações com o intuito de preparar o ambiente para começar a cobrança da Dívida Ativa, sendo um processo que teve vários projetos, conforme verifica-se na Figura 3. Esse conjunto de legislações culminou na possibilidade de protesto extrajudicial da CDA conforme Decreto Executivo Municipal no 44 de 03 de abril de 2014.

Segundo o relato R3, assim que a Lei Federal no 12.767/2012 foi aprovada, os servidores da Secretaria de Finanças propuseram aos gestores a implantação da nova modalidade de cobrança no município de Santa Maria. Como produto legislativo inicial, o Decreto Executivo Municipal n044/2014(Santa Maria, 2014) 
teve seu escopo baseado na interação entre a Prefeitura, a Câmara de Diretores Lojistas - CDL e o Cartório de Registro de Protestos.

A legislação comprova as opções realizadas, pois em 03 de abril de 2014, o Decreto Executivo Municipal n044/2014 (Santa Maria, 2014) estabeleceu, inicialmente, que débitos com valores até $\mathrm{R} \$ \mathbf{1 0 . 0 0 0 , 0 0}$ (Dez mil reais) fossem encaminhados ao SCPC, e acima desse valor ao Cartório de Protesto. Posteriormente, em 03 de janeiro de 2015, foi editado o Decreto Executivo Municipal no 09/2015 (Santa Maria, 2015), o qual alterou para 1.500 UFMS, na época equivalente a $R \$ 4.083,00$, a segregação de valores. Finalmente, em 19 de agosto de 2015, o Decreto Executivo Municipal no 76/2015 (Santa Maria, 2015), estabelece que "os créditos inscritos em Dívida Ativa, independente de valor, serão encaminhados para inscrição junto ao SCPC e registro no Cartório de Protesto.

A entrevista R1 ainda relata que os trabalhos preparatórios a cobrança extrajudicial das CDA via protesto consistiram na organização dos sistemas de informática para integrar o CADIM a base de dados do SCPC, que em Santa Maria é operado pelo CDL. O mesmo não ocorrera com o Cartório de Registro de Protestos, com o qual a tramitação dos documentos se dava por processos físicos. As dificuldades tecnológicas, aliadas a maior eficiência da cobrança do SCPC culminaram na preferência pelo sistema operado pela CDL em detrimento a cobrança realizada pelo cartório de acordo com o entrevistado R3.

O trabalho de cobrança via SCPC teve inclusões iniciais que foram graduais e de forma cautelosa conforme relata o entrevistado R4. A entrevista R3 também confirma o procedimento, "logo no início ele era manual", após se "exigiu que a empresa fizesse o sistema", e "a gente começou aos poucos e depois foi aumentando [...] não colocamos duma hora para outra mil, nós colocamos aos pouquinhos e começamos a ver no que ia dar de retorno, realmente o medo ele existe, porque tu não sabes o que tu tens dentro do teu cadastro".

Os respondentes foram unânimes em identificar os resultados positivos na arrecadação advindos da ação de cobrança via SCPC, tal percepção é declarada na entrevista R1 que diz "a gente notou que até inadimplência da dívida corrente diminuiu, com a possibilidade de ir para o SCPC". A entrevista R9 afirma que "é uma bela forma de compelir a ele vir aqui, e parcelar, enfim resolver o problema".

Quanto ao perfil do contribuinte em que a nova metodologia de cobrança foi mais eficaz, a maioria dos respondentes relataram que são as pessoas físicas, proprietárias de imóveis, que recebem até cinco salários mínimos, dependentes da não restrição de créditos junto ao SCPC ou outras instituições financeiras e que estão economicamente ativos. De acordo com a percepção do entrevistado R6, essa nova postura da PMSM impactou o comportamento do contribuinte na diminuição da inadimplência, na atualização cadastral, na comunicação com a autoridade tributária municipal e na cultura.

Também se observa a interação entre o contribuinte e o fisco tanto na cobrança por melhores serviços públicos quanto na resposta do município às exigências das pessoas. Essa relação pode favorecer a observância fiscal voluntária, conforme lecionado por Kirchler et al. (2008). A entrevista R8 revela essa interação: "Como que o cemitério, cobrava a demanda do cemitério, e o município não dava o serviço de limpeza do cemitério. Há muita reclamação pelo cliente, que é o contribuinte, no sentido de que ele está pagando, está inscrito no SCPC, mas que lá na rua dele a Prefeitura não passa nem o caminhão do lixo." 
Além dos impactos sobre o comportamento do contribuinte e da interação entre a Administração Tributária e seus administrados, diversos fatores positivos em relação à cobrança extrajudicial de CDA via protesto junto ao SCPC são percebidos pelos entrevistados. Questões como o baixo custo da cobrança via SCPC aliado ao baixo número de processos judiciais perdidos em razão da cobrança, favoreceram a implantação dessa forma de gestão fiscal. 0 Tabela 5 sintetiza as vantagens e limitações da implantação do SCPC na Prefeitura de Santa Maria.

Tabela 5 - Vantagens e limitações do SCPC segundo a percepção dos entrevistados.

\begin{tabular}{|c|c|c|c|c|c|c|c|c|c|c|}
\hline Vantagens e limitações do SCPC & $\mathbf{R} \mathbf{1}$ & $\mathbf{R 2}$ & R3 & R4 & R5 & R6 & R7 & $\mathbf{R 8}$ & R9 & R10 \\
\hline \multicolumn{11}{|l|}{ VANTAGENS } \\
\hline Maior eficácia em relação ao cartório & $x$ & & & & & & & & & \\
\hline Rapidez na restrição ao crédito & $x$ & & & & & & & & & \\
\hline Baixo custo de cobrança & $x$ & & & & & & & & & \\
\hline Eficiência & & $x$ & & & $x$ & $x$ & & & & \\
\hline Educação/Cultura do contribuinte & & & & & $\mathrm{X}$ & & $x$ & & & \\
\hline Equidade na cobrança/Justiça fiscal & & & & & $\mathrm{x}$ & & $x$ & & & \\
\hline Apoio na atualização cadastral da Prefeitura & & & & & & $\mathrm{x}$ & & & & \\
\hline Alta taxa de retorno para o município & & & & & & $\mathrm{x}$ & & $\mathrm{x}$ & & \\
\hline Tramitação informatizada & & & & & & & & $\mathrm{x}$ & & \\
\hline Baixo índice de perdas em ações judiciais & & & & & & & & & $x$ & \\
\hline Meio mais efetivo de coerção & & & & & & & & & & $x$ \\
\hline $\begin{array}{l}\text { Realiza as tarefas que seriam obrigação do } \\
\text { município }\end{array}$ & & & & & & & & $\mathrm{X}$ & & \\
\hline \multicolumn{11}{|l|}{ LIMITAÇÕES } \\
\hline Necessita de cadastro atualizado & & & $x$ & & & & & & & \\
\hline
\end{tabular}

Fonte: Elaborado pelos autores.

Outro importante fator se deve a efetividade da cobrança via SCPC em relação as dívidas inferiores a 230 UFM, dispensadas de execução fiscal. Conforme respondente R10: "Mas assim, realmente essas dívidas menores, que, que a pessoa acaba sendo inscrita no SCPC, ela deu um implemento maior, que seriam dívidas que não seriam ajuizados ela deu, um Plus assim, realmente de receita, um pouco né, porque o valor do crédito é pequeno.". Dessa forma, a PMSM encontrou nesse mecanismo uma eficaz forma de recuperar os créditos inadimplidos, melhorando a gestão municipal como um todo. A entrevista R3 demonstra essa percepção, a qual é encontrada também nos demais respondentes.

Então mesmo que tu digas assim, a Prefeitura Municipal de Santa Maria não tem uma estrutura para ficar cobrando, mas o próprio SCPC é uma ajuda, porque ele está notificando, em outras palavras, para nós, o que nós não temos condições de fazer. [R3]

A percepção da efetividade em relação a cobrança de pequenos valores possibilitou que em maio de 2017, fosse alterado o valor estabelecido para dispensa de execução fiscal de 230 UFMs $(2017$ - R\$ 742,48), estabelecido pela Lei Municipal no 4954, de 04 de dezembro de 2006 (Santa Maria, 2006), para 500 Unidades Fiscais Municipais - UFM (2017 - R\$ 1.614,10), de acordo com a Lei 
Municipal $n^{\circ}$ 6129, de 19 de maio de 2017 (Santa Maria, 2017). A alteração do limite propicia uma redução do número de execuções fiscais gerando economia para o município, possível em vista da implementação das ferramentas de cobrança administrativa via SCPC.

Por fim, verifica-se que a implantação da cobrança via SCPC decorreu de um processo de melhorias no sentido de tornar a cobrança dos débitos, tanto corrente, quanto ativa, mais efetiva. Esse processo é de longa data, e iniciou-se com o Projeto do "Projeto Pague Já", o qual agiliza as cobranças via Fórum, inclusive com bloqueios de valores; passou por vários programas de recuperação de receita, via desconto de multas e juros; instituição de descontos para contribuintes em situação de total adimplência; até a cobrança através do SCPC. Além disso, os respondentes demonstraram que o envio dos débitos para o SCPC foi uma ação ousada, que causa orgulho pelo pioneirismo.

\section{CONSIDERAÇÕES FINAIS}

A pesquisa apontou para a essencialidade da receita própria para a realização dos serviços públicos da Prefeitura de Santa Maria. Todavia, a ação municipal fica limitada pela alta inadimplência dos contribuintes, o que implica também na maior dependência financeira de outros entes. Dessa forma, as ações de melhoria da administração tributária devem ser implementadas. $O$ arcabouço teórico demonstrou que para cada perfil de contribuinte deve existir uma ação correspondente, assim, os fiéis cumpridores das suas obrigações devem ser orientados e estimulados a permanecerem como tal, bem como os maus pagadores devem ser objeto de auditoria, fiscalização e aplicação de penalidades.

Segundo a percepção dos entrevistados, a inadimplência no município estudado apresenta como causas principais os fatores macroeconômicos como a crise, as próprias deficiências da administração tributária municipal, a percepção do contribuinte sobre os bens e os serviços públicos prestados pela PMSM, além do perfil e comportamento do contribuinte. Nesse sentido, observa-se que são necessárias a aplicação em conjunto das teorias constantes nos paradigmas "do serviço" e "do crime" como esteio para as observâncias fiscais voluntária e forçada, respectivamente.

Além das ações no campo das políticas públicas para o fisco municipal, a pesquisa revela ser necessária melhorias na infraestrutura, qualificação de pessoal, adequação e padronização de processos, melhoria da comunicação fiscocontribuinte, bem como o intensivo uso da tecnologia da informação. Apesar das demonstrações de falhas na estrutura de cobrança do município, os respondentes são unânimes em destacar as ações de cobrança promovidas com os recursos disponíveis, inclusive quanto ao envio de débitos para o SCPC.

Pode-se conjecturar que essa nova modalidade de cobrança pode contribuir para a melhoria da eficiência das administrações tributárias municipais, favorecendo a recuperação de créditos inadimplidos e a criação de uma cultura de pagamento dos tributos, em vista das consequências advindas. Além disso, detectou-se que esse processo implantado na PMSM constitui em "boas práticas" na área da arrecadação, servindo de modelo para vários municípios no estado, para a melhoria da governança nas gestões públicas brasileiras. 
Como limitação ao estudo, evidencia-se a dificuldade de obtenção de dados segregados de receita para comprovar através de ferramentas estatísticas a relação entre as ações municipais e o efetivo incremento na arrecadação própria. Assim, em estudos futuros sugere-se a verificação estatística dos resultados, bem como a replicação do estudo em outros contextos e a análise das ações segundo a percepção dos contribuintes. 


\title{
Analysis of extrajudicial collection in the municipality of Santa Maria (RS)
}

\begin{abstract}
The Municipality of Santa Maria (RS), seeking to increase its own tax revenues, implemented, after the validity of Federal Law 12.767/2012, the collection of debts through the sending of Active Debt Certificates for extrajudicial protest. The objective of this article was to analyze the panorama of this new modality of collection according to the perception of the agents of the municipal tax administration, from 2014 to 2017. For that, 10 interviews were carried out, which after their transcription were submitted to content analysis to systematize the data. The units of analysis were based on the Brazilian and international literature dealing with tax compliance and its paradigms. The analysis pointed out that the interviewees mostly highlighted the positive aspects of this collection, which consolidates itself as an effective tool to fight against delinquency before the City Hall. As limitations, the difficulty of obtaining segregated revenue data is evidenced, suggesting for future studies the statistical confirmation of the information as well as the analysis of the perception from the perspective of the taxpayers.
\end{abstract}

KEY WORDS: Tax Administration; delinquency; Active Debt; Extra Judicial Protest; Municipality. 


\section{REFERÊNCIAS}

Afonso, J. R. R., Araujo, E. A., \& Nóbrega, M. A. R. da. (2013). IPTU no Brasil: Um Diagnóstico Abrangente. Brasília/DF e Rio de Janeiro/RJ: Instituto Brasiliense de Direito Público IDP Ltda e FGV Projeto.

Amaro, L. (2016). Direito Tributário Brasileiro. 21. ed. São Paulo: Saraiva.

Bardin, L. (2011) Análise de conteúdo. 70. Ed. São Paulo.

Bird, R. M. (2014). Administrative Dimensions of Tax Reform. Annals of Economics and Finance, 15(2), 269-304.

BRASIL. (1988). Constituição da República Federativa de 1988. Recuperado em 17 outubro, 2017 de

http://www.planalto.gov.br/ccivil_03/Constituicao/ConstituicaoCompilado.htm.

(1966). Lei $n^{\circ}$ 5.172, de 25 de outubro de 1966. Dispõe sobre o Sistema Tributário Nacional e institui Normas Gerais de Direito Tributário aplicáveis a União, Estados e Municípios. Recuperado em 15 maio, 2016 de http://www.planalto.gov.br/ccivil_03/leis/l5172.htm.

(2015). Lei no 13.105, de 16 de março de 2015. Código de Processo Civil. Recuperado em 29 outubro, 2017 de

http://www.planalto.gov.br/ccivil_03/_ato2015-2018/2015/lei/l13105.htm.

. (1997). Lei 9.492, de 10 de setembro de 1997. Define competência, regulamenta os serviços concernentes ao protesto de títulos e outros documentos de dívida e dá outras providências. Recuperado em 12 agosto, 2017 de http://www.planalto.gov.br/ccivil_03/leis/L9492.htm.

(1980). Lei no 6.830, de 22 de setembro de 1980. Dispõe sobre a cobrança judicial da Dívida Ativa da Fazenda Pública, e dá outras providências. Recuperado em 29 outubro, 2017 de http://www.planalto.gov.br/ccivil_03/leis/L6830.htm.

(2012). Lei 12.767, de 27 de dezembro de 2012. Dispõe sobre a extinção das concessões de serviço público de energia elétrica e a prestação temporária do serviço e sobre a intervenção para adequação do serviço público de energia elétrica; altera as Leis nos 8.987, de 13 de fevereiro de 1995, 11.508, de 20 de julho de 2007, 11.484, de 31 de maio de 2007, 9.028, de 12 de abril de $1995,9.492$, de 10 de setembro de 1997, 10.931, de 2 de agosto de 2004, 12.024, de 27 de agosto de 2009, e 10.833, de 29 de dezembro de 2003; e dá outras 
providências. Recuperado em 12 agosto, 2017 de

http://www.planalto.gov.br/ccivil_03/_Ato2011-2014/2012/Lei/L12767.htm.

. (2017). TESOURO NACIONAL. Balanço Geral da União. Demonstrações Contábeis Consolidadas da União, 2o Trimestre de 2017. Brasília, 2017. Recuperado em 15 outubro, 2017 de http://www.tesouro.fazenda.gov.br/documents/10180/243309/DCON_2017_Tri mestre_2.pdf/d60802cf-9f03-432d-9e16-5f2ff44cb04e.

(2017). TESOURO NACIONAL. Balanço Geral da União. Demonstrações Contábeis Consolidadas da União, 2o Trimestre de 2017. Brasília, 2017. Recuperado em 15 outubro, 2017 de http://www.tesouro.fazenda.gov.br/documents/10180/243309/DCON_2017_Tri mestre_2.pdf/d60802cf-9f03-432d-9e16-5f2ff44cb04e.

Elch, C. A., Pimentel, G. R., Moura, M. T. de, \& Casanova Neto, R. C. (2014). Aprimoramento da sistemática atual de Execução Fiscal: alternativas pré e pósinscrição do Crédito Tributário em Dívida Ativa. Fórum Fiscal dos Estados Brasileiros - FFEB. Brasília: Esaf.

Freire, A. C., \& Freire, F. M. (2014). Causas da Inadimplência nas Instituições de Ensino Superior e Meios de Reduzi-la. Revista Eletrônica de Educação da Faculdade Araguaia - RENEFARA, 5(5), 247-259.

Jesus, T. C. A., \& Rocha, W. (2015). Dívida Ativa: Exame do Crescimento do Estoque da Dívida Ativa nos Município e as Alternativas para a sua Redução. Revista Técnica CNM, 34-48.

Kirchler, E., Hoelzl, E., \& Wahl, I. (2008). Enforced Versus Voluntary Tax Compliance: The 'Slippery Slope Framework. Journal of Economic Psychology, 29(2), 210-225.

Rizzardo, A. (2015). Direito das Obrigações. 8. ed. Rio de Janeiro: Forense.

Santa Maria. (2006). Lei Municipal no 4954, de 04 de dezembro de 2006. Dispõe sobre a Cobrança de Débitos inscritos em Dívida Ativa.

(2009). Lei Municipal no 5247, de 16 de novembro de 2009. Cria o Cadastro de Informações Municipais - Cadim. 
. (2017). Lei Municipal no 6128, de 19 de maio de 2017. Dispões sobre o Cadastro de Informações Municipais - Cadim e revoga a Lei Municipal no 5247, de 16 de novembro de 2009.

. (2017). Lei Municipal no 6129, de 19 de maio de 2017. Altera a Lei no 4954, de 04 de dezembro de 2006.

. (2013). Decreto Executivo Municipal no 100, de 30 de agosto de 2013. Dispõe sobre o Regimento Interno da Secretaria de Município de Finanças, de conformidade com a Lei Municipal no 5189/09 e alterações, e dá outras providências.

. (2014). Decreto Executivo Municipal no 044, de 03 de abril de 2014. Dispõe sobre Protesto Extrajudicial e a inscrição no Serviço de Proteção ao Crédito - SCPC de "Créditos Tributários e não Tributários do Município".

. (2015). Decreto Executivo Municipal no 09, de 21 de janeiro de 2015. Altera o Decreto Executivo № 044/14, de 03 de abril de 2014.

(2015). Decreto Executivo Municipal no 76, de 19 de agosto de 2015. Altera o art. 2ㅇ do Decreto Executivo № 044/14, de 03 de abril de 2014.

. (2016). Balancete de Receita de Dezembro 2016. 2016. Disponível em: <http://www.santamaria.rs.gov.br/docs/transparencia/2016/trd_20161231574.pdf>. Acesso em: 03 out. 2017.

. (2017). Secretária de Município de Finanças. Superintendência de Receita. Relatório de Débitos por Natureza de Receita. 31.10.2017.

. (2017). Secretária de Município de Finanças. Superintendência de Receita. Relatório de inclusão no SCPC. 2014. 2015. 2016.2017

Silva, F. P. (2015). Observância Tributária: Integrando paradigmas em busca de mais conformidade fiscal. Dissertação (Mestrado em Ciências) - Universidade de São Paulo, São Paulo.

Souza, T. F. (2015). O protesto extrajudicial de certidão de dívida ativa após a edição da Lei no 12.767/2012. Revista de Doutrina da 4ạ Região, 64, 1-22. 
TCE, Tribunal de Contas do Estado. (2014). Cartilha de Racionalização da Cobrança da Dívida Ativa Municipal. 2014. Recuperado em 29 outubro, 2017 de http://www.tjrs.jus.br/site/imprensa/destaques/doc/Cartilha_racionalizacao_dez _2014.pdf.

Tyler, T. R. (2006). Psychological Perspectives on Legitimacy and Legitimation. Annual Review of Psychology, 57, 375-400.

Viol, A. L. (2015). A Administração Tributária Moderna e a Maximização do Cumprimento Tributário: Algumas Reflexões Sobre o Caso Brasileiro. Revista da Receita Federal: Estudos Tributários e Aduaneiros, 1(2), 50-82.

Recebido: 30 nov. 2019

Aprovado: 28 jan. 2020

DOI:10.3895/rbpd.v9n2.9278

Como citar: GERING, S. M. P.; NOGUEIRA, R. R.; PONTELLI, G. E.; PINTO, N. G. M., LOCK, F. N. Análise

da cobrança extrajudicial no município de Santa Maria (RS). R. bras. Planej. Desenv. Curitiba, v. 9, n. 2, p.

192-213, mai./ago. 2020. Disponível em: <https://periodicos.utfpr.edu.br/rbpd>. Acesso em: XXX.

Correspondência:

Nelson Guilherme Machado Pinto

Av. Roraima no 1000 Cidade Universitária Bairro - Camobi - Santa Maria, RS

Direito autoral: Este artigo está licenciado sob os termos da Licença CreativeCommons-Atribuição 4.0

Internacional. 